\title{
Capsule Commentary for Teo et al., The Importance of "Being There": a Qualitative Study of What Veterans with Depression Want in Social Support
}

Kieran McAvoy, M.D.

Medical College of Wisconsin, Milwaukee, WI, USA

$\mathrm{J}$ Gen Intern Med 35(7):2249

DOI: $10.1007 / \mathrm{s} 11606-020-05844-9$

() Society of General Internal Medicine 2020

$\mathrm{T}$ eo et al. [1] aimed to describe how the patient's social support impacted his or her depression care. They conducted qualitative interviews of 30 subjects with at least one positive depression screen, one primary care visit, and one close relationship. The authors identified "Being There" as their main theme, through the descriptions of close support, participation in depression care, and barriers to involving close support. The concept of "Being There" essentially involves either a literal presence, active monitoring of patient status, or perceived availability. Successful close contacts had the ability to "sense" the patient's emotional state and were able to communicate indirectly about it. Barriers preventing patients from achieving this goal were concern for overburdening close supports, fear of provoking anxiety, and a tendency to manage depression without assistance.

Given that this is a qualitative work, it was not possible to assess the clinical outcomes of patients with support that fulfilled the criteria of "Being There." Did those with better supports have improved adherence to therapy? Did the $63 \%$ of subjects who thought seriously about suicide decide not to go through with it due to superior social support? While previous research has expounded on the concept that those with better perceived social support overall have improved clinical outcomes [2], it is unclear how the characteristics of "Being There" are different from previously cited social support. Furthermore, it would have been interesting if the barriers had been examined with respect to the perceptions of the

Published online April 24, 2020 supporter. While "caregiver burnout" is a prevalent problem, few studies have focused on caregivers of patients with depression. A cross-sectional study by Chai et al. [3] found that $28.5 \%$ of caregivers for those with depression experienced depressive symptoms themselves. While further research on this topic is warranted, ensuring that these close supports are well equipped not only may improve the health of the patients but also that of the caregiver. Interventions should be designed to assess the impact of "Being There" as well as monitoring and improving the "well-being" of the close support.

Corresponding Author: Kieran McAvoy, M.D.; Medical College of Wisconsin, Milwaukee, WI, USA (e-mail: kmcavoy@mcw.edu).

Compliance with Ethical Standards:

Conflict of Interest: The author declares that she does not have a conflict of interest.

\section{REFERENCES}

1. Teo AR, Marsh HE, Ono SS, Saha S, Nicolaidis C, Dobscha SK. The Importance of "Being There": A Qualitative Study of What Veterans with Depression Want in Social Support. J Gen Intern Med DOI: https://doi. org/10.1007/s11606-020-05692-7

2. Wang, J., Mann, F., Lloyd-Evans, B. et al. Associations between loneliness and perceived social support and outcomes of mental health problems: a systematic review. BMC Psychiatry 18, 156 (2018).

3. Chai YC, Mahvadevan R, Guan Ng C, Chan LF. et al. Caregiver depression: The contributing role of depression in patients, stigma, social support and religiosity. International Journal of Social Psychiatry 64, 6 (2018).

Publisher's Note: Springer Nature remains neutral with regard to jurisdictional claims in published maps and institutional affiliations. 